\title{
Ocorrência de dermatófitos em amostras de unhas, pés e mãos coletadas de estudantes universitários
}

\author{
Occurrence of dermatophyte, in nails, feet and \\ hands of universitary students
}

\author{
Emersom Roberto Siqueira ${ }^{1}$, Joseane Cristina Ferreira ${ }^{1}$, \\ Claudia Maria Leite Maffei $^{2}$ e Regina Celia Candido ${ }^{1}$
}

\begin{abstract}
RESUMO
Este trabalho teve como objetivo, avaliar a presença de dermatófitos, especificamente em unhas, pés e mãos de estudantes universitários com e sem lesões sugestivas de dermatofitose. Foram coletadas 280 amostras dessas regiões, das quais 31 (11,1\%) apresentaram positividade apenas pelo exame direto, e 20 (7,1\%) tiveram, além do exame direto positivo, crescimento de dermatófito, mediante cultivo da amostra biológica. T. rubrum foi o dermatófito isolado com maior freqüência (80\%), seguido por T. mentagrophytes (20\%). Considerando os sítios analisados neste trabalho, a ocorrência de dermatófitos foi observada em 10,4\% nas unhas dos pés, 5\% nas escamas de pés, 2,5\% nas unhas das mãos e apenas 0,4\% nas escamas das mãos.
\end{abstract}

Palavras-chaves: Dermatófitos. Trichophyton rubrum. Trichophyton mentagrophytes.

\section{ABSTRACT}

The objective of this paper was to evaluate the occurrence of dermatophytes, specifically in the nails, feet and hands of university students with and without lesions. Two hundred and eighty samples were collected; 31 (11.1\%) were positive by direct examination, while only 20 (7.1\%) showed dermatophyte growth in culture, as well as direct positive examination. Trichophyton rubrum was the most frequently isolated (80\%) dermatophyte followed by T. mentagrophytes (20\%). Considering the sites analyzed, dermatophyte occurrence was: $10.4 \%$ in toenails, 5\% in foot skin, $2.5 \%$ in fingernails and $0.4 \%$ in hand skin.

Key-words: Dermatophytes. Trichophyton rubrum. Trichophyton mentagrophytes.

Os dermatófitos constituem um grupo de fungos que, em vida parasitária, têm a capacidade de invadir tecidos queratinizados de humanos e outros animais, causando infecções denominadas dermatofitoses. As dermatofitoses, cujos agentes etiológicos pertencem aos gêneros Trichophyton, Microsporum e Epidermophyton, constituem um dos grupos de infeções fungicas mais freqüentes na prática dermatológica. Condições climáticas favoráveis à implantação das mesmas são observadas em diversas regiões do Brasil. A maioria dessas infecções encontra-se primariamente concentrada em regiões tropicais, onde persiste um clima quente e úmido, causando relevante problema de saúde pública ${ }^{3}$.

0 gênero Trichophyton é composto por diversas espécies, dentre as quais destaca-se pela frequiência de isolamento T. rubrum, que pode produzir praticamente todos os quadros clínicos de dermatofitose, tendo como características principais à tendência para cronicidade e a resistência aos tratamentos convencionais ${ }^{4}$.

0 presente trabalho teve como objetivo verificar a ocorrência e a etiologia de dermatófitos em grupo de estudantes universitários.

\footnotetext{
1. Faculdade de Ciências Farmacêuticas de Ribeirão Preto da Universidade de São Paulo, Ribeirão Preto, SP. 2. Faculdade de Medicina de Ribeirão Preto da Universidade de São Paulo, Ribeirão Preto, SP.

Endereço para correspondência: Dra. Regina Célia Cândido. Av. do Café s/n, 14040-903 Ribeirão Preto, SP.

Telefax: $55163602-4725$

e-mail: rcandido@fcfrp.usp.br

Recebido para publicação em 25/2/2005
} 


\section{MATERIAL E MÉTODOS}

Entre os meses de julho de 2002 e julho de 2003 foram coletadas 280 amostras de unhas ou pele das regiões dos pés ou mãos de 280 estudantes universitários, entre 18 a 25 anos de idade. Os indivíduos incluídos neste estudo foram divididos em: grupo I (GI), 131 universitários (56 homens e 75 mulheres) aparentemente saudáveis sem lesões ungueais, interdigitais, palmares ou plantares; e grupo II (GII), 149 universitários (72 homens e 77 mulheres) com lesões ungueais, e/ou interdigitais, e/ou palmares e/ou plantares, suspeitas de dermatofitoses. Todos receberam explicação acerca da investigação e consentiram na sua inclusão na pesquisa, preenchendo um protocolo de permissão e avaliação. 0 projeto foi aprovado pelos Comitês de Ética e Pesquisa (CEP) da Faculdade de Ciências Farmacêuticas de Ribeirão Preto-USP e Universidade de Franca.

As amostras para pesquisa de dermatófitos foram obtidas por raspagem superficial com bisturi esterilizado, após antisepsia local com gaze embebida em etanol $70 \%$. 0 exame micológico direto de todos os materiais coletados foi realizado com KOH a 30\% acrescido de tinta Parker azul permanente. 0 isolamento de dermatófitos das amostras foi realizado em ágar Sabouraud dextrose, contendo 100mg/L de cloranfenicol, e em ágar Mycosel, sob incubação a $30^{\circ} \mathrm{C}$, até completar um mês. A identificação dos gêneros e espécies foi realizada de acordo com as características macro e microscópicas das colônias e por testes de hidrólise da uréia e perfuração in vitro de pêló .

\section{RESULTADOS}

Das 280 amostras biológicas coletadas, a ocorrência de dermatófitos foi observada em 51 (18,2\%) estudantes, assim determinada: pela positividade apenas do exame direto, $31(11,1 \%)$ estudantes, e pela positividade do exame direto aliada ao isolamento do dermatófito após o cultivo da amostra biológica, $20(7,1 \%)$ estudantes.

Dentre as 131 amostras do grupo controle, fungos filamentosos com hifas características de dermatófitos foram observados, considerando apenas em exame direto, 5 (3,8\%) amostras positivas e quando considerado exame direto e cultura, somente $1(0,8 \%)$ amostra apresentou-se positiva, para T. mentagrophytes (Tabela 1 ).

Das 149 amostras colhidas de estudantes do grupo com lesões, $26(17,4 \%)$ apresentaram somente exame direto positivo, e $19(12,7 \%)$ amostras apresentaram exame direto

Tabela 1- Resultados dos exames micológicos das amostras biológicas nos grupos I (controle) e grupo II (com lesão).

\begin{tabular}{lcccc}
\hline & & Exame direto \\
& Amostras \\
coletadas & Exame direto & positivo & Espécies isoladas \\
& & & Cultura & \\
\hline Grupo I & 131 & 5 & 1 & T. mentagrophytes (1) \\
Grupo II & 149 & 26 & 19 & T. rubrum (16) \\
& & & & T. mentagrophytes (3) \\
\hline
\end{tabular}

positivo e cultura positiva para dermatófitos (Tabela 1). Foi identificado T. rubrum em 16 (84,2\%) amostras e T. mentagrophytes em $3(15,8 \%)$ amostras.

\section{DISCUSSÃo}

Estima-se que cerca de 10 a 15\% da população mundial, pode ser infectada por dermatófitos no decorrer de suas vidas ${ }^{2}$. Neste trabalho, observamos uma ocorrência de dermatófitos de $18,2 \%$ na população estudada $e$ as unhas, além de representaram o maior número de amostras biológicas colhidas entre os estudantes, apresentaram a maior proporção de positividade para dermatófitos $(12,9 \%)$.

Em relação ao exame direto positivo para dermatófitos, dependendo do grupo populacional estudado, a literatura indica percentual variável: $14,6 \%, 20 \%$ e $53 \%{ }^{28}$. Em relação à cultura positiva com exame direto positivo, os índices também são variáveis: $35,6 \%, 66,7 \%$ e $70,4 \%{ }^{28}$. Nossos resultados globais mostraram taxas menores que as citados na literatura, $11,1 \%$ para exame direto positivo e 7,1\% para exame direto e cultura positiva. Acreditamos que esses índices baixos foram favorecidos pelo grupo controle, pois se considerarmos apenas o grupo de estudantes com manifestações clínicas características de dermatofitose, 0 índice de amostras positivas pelo exame direto sobe para 30,2\% (45 amostras do total de 149).

Embora Reis ${ }^{7}$ descarte a necessidade de exame micológico para pacientes com ausência de lesões, o presente trabalho demonstrou que de 131 estudantes assintomáticos, grupo controle sem lesões, em 6 (4,6\%) foram observados a presença de dermatófitos, inclusive de $1(0,8 \%)$, foi possível o isolamento do dermatófito em meio de cultura, correspondendo a espécie T. mentagrophytes. No grupo de estudante com lesões, 26 amostras tiveram exame direto positivo e cultura negativa. Segundo Merlin e cols, a discordância entre exame direto positivo e cultura negativa em estudos de micoses superficiais não deve ser considerada para fins diagnósticos 5 .

Dos 26 estudantes que tiveram amostras positivas pelo exame direto com cultura negativa, 9 (34,6\%) estavam ou já tinham feito uso de antifúngicos, o que provavelmente inibiu o crescimento do fungo.

A partir das amostras biológicas colhidas de todos os universitários em estudo, o único gênero isolado foi Trichophyton, apresentando predominância da espécie T. rubrum (80\%), seguida de T. mentagrophytes $(20 \%)$. Mezzari ${ }^{6}$ relatou o predomínio de T. rubrum $(55,3 \%)$ seguido por T. mentagrophytes $(21,5 \%)$ entre os dermatófitos encontrados em amostras de pele, pêlos e unhas, na Cidade de Porto Alegre, Brasil. As espécies T. rubrum e T. mentagrophytes, de modo geral, são as mais freqüentemente isoladas das lesões de tinea unguium, tinea pedis e tinea manuum ${ }^{13}$.

Os resultados deste trabalho justificam a realização de estudos mais amplos, que possam atingir um maior número de pessoas, e com isso, produzir um levantamento epidemiológico mais significativo, e mostra a presença de dermatófitos em indivíduos assintomáticos. 


\section{REFERÊNCIAS BIBLIOGRÁFICAS}

1. Aman S, Harroon TS, Hussain I, Bokhari MA, Khurshid K. Tinea unguium in Lahore, Pakistan. Medical Mycology 39:177-180, 2001.

2. Brilhante RSN, Paixão GC, Salvino LK, Diogenes MJ, Bandeira SP, Rocha MF, dos Santos JB, Sidrim JJ. Epidemiologia e ecologia das dermatofitoses na cidade de Fortaleza: o Trichophyton tonsurans como importante patógeno emergente da Tinea capitis. Revista da. Sociedade Brasileira de Medicina Tropical 33: 417-425, 2000.

3. Chimelli PAV, Sofiatti AA, Nunes RS, Martins J. Dermatophyte agents in the city of São Paulo, from 1992 to 2002. Revista do Instituto de Medicina Tropical de São Paulo 45:259-263, 2003.
4. Lacaz CS, Porto E, Heins-Vaccari EM, Melo NT. Guia para identificação: Fungos, Actinomicetos e Algas de interesse médico. SARVIER-FAPESP, São Paulo, 1998.

5. Merlin K, Kilkenny M, Plunkett A, Marks R. The prevalence of common skin conditions in Australian school students: 4 Tinea pedis. The British Journal Dermatology 140:897-901, 1999.

6. Mezzari A. Frequency of dermatophytes in the metropolitan area of Porto Alegre, RS, Brazil. Revista do Instituto de Medicina Tropical de São Paulo 40:71-76, 1998.

7. Reis HHT, Azulay RD, Marinho DEA. O chamado "pé de atleta": aspectos micológicos e epidemiológicos. Anais Brasileiros de Micologia 57: 99-100, 1982.

8. Soares MMSR, Cury AE, Schreiber AZ. Micose superficial da região podal em indivíduos considerados imunocomprometidos. Anais Brasileiros de Dermatologia 70: 211-217, 1995. 